\title{
Lactococcus lactis Thioredoxin Reductase Is Sensitive to Light Inactivation
}

Björnberg, Olof; Viennet, Thibault; Skjoldager, Nicklas; Curovic, Aida; Nielsen, Kristian Fog; Svensson, Birte; Hägglund, Per

\section{Published in:}

Biochemistry

Link to article, DOI:

10.1021/bi5013639

Publication date:

2015

Document Version

Publisher's PDF, also known as Version of record

Link back to DTU Orbit

Citation (APA):

Björnberg, O., Viennet, T., Skjoldager, N., Curovic, A., Nielsen, K. F., Svensson, B., \& Hägglund, P. (2015). Lactococcus lactis Thioredoxin Reductase Is Sensitive to Light Inactivation. Biochemistry, 54(8), 1628-1637. https://doi.org/10.1021/bi5013639

\section{General rights}

Copyright and moral rights for the publications made accessible in the public portal are retained by the authors and/or other copyright owners and it is a condition of accessing publications that users recognise and abide by the legal requirements associated with these rights.

- Users may download and print one copy of any publication from the public portal for the purpose of private study or research.

- You may not further distribute the material or use it for any profit-making activity or commercial gain

- You may freely distribute the URL identifying the publication in the public portal 


\title{
Lactococcus lactis Thioredoxin Reductase Is Sensitive to Light Inactivation
}

\author{
Olof Björnberg, ${ }_{\dagger}^{\dagger}$ Thibault Viennet, ${ }^{\dagger}$ Nicklas Skjoldager, ${ }^{\dagger}$ Aida Ćurović, ${ }^{\dagger}$ Kristian Fog Nielsen, ${ }^{\ddagger}$ \\ Birte Svensson, ${ }^{\dagger}$ and Per Hägglund ${ }^{*}{ }^{\dagger}$ \\ †Enzyme and Protein Chemistry, Department of Systems Biology, Technical University of Denmark, Building 224, Søltofts Plads, \\ DK-2800 Kongens Lyngby, Denmark \\ "Metabolic Signaling and Regulation group, Department of Systems Biology, Technical University of Denmark, Building 221, Søltofts \\ Plads, DK-2800 Kongens Lyngby, Denmark
}

\section{Supporting Information}

ABSTRACT: Thioredoxin, involved in numerous redox pathways, is maintained in the dithiol state by the nicotinamide adenine dinucleotide phosphate-dependent flavoprotein thioredoxin reductase (TrxR). Here, TrxR from Lactococcus lactis is compared with the well-characterized TrxR from Escherichia coli. The two enzymes belong to the same class of low-molecular weight thioredoxin reductases and display similar $k_{\text {cat }}$ values $\left(\sim 25 \mathrm{~s}^{-1}\right)$ with their cognate thioredoxin. Remarkably, however, the L. lactis enzyme is inactivated by visible light and furthermore reduces molecular oxygen 10 times faster than $E$. coli TrxR. The rate of light inactivation under standardized conditions $\left(\lambda_{\max }=460 \mathrm{~nm}\right.$ and 4 ${ }^{\circ} \mathrm{C}$ ) was reduced at lowered oxygen concentrations and in the presence of iodide. Inactivation was accompanied by a distinct spectral shift of the flavin adenine dinucleotide (FAD) that remained firmly bound. High-resolution mass spectrometric analysis of heat-extracted FAD from light-damaged TrxR revealed a mass increment of $13.979 \mathrm{Da}$, relative to that of unmodified FAD, corresponding to the addition of one oxygen atom and the loss of two hydrogen atoms. Tandem mass spectrometry confined the increase in mass of the isoalloxazine ring, and the extracted modified cofactor reacted with dinitrophenyl hydrazine, indicating the presence of an aldehyde. We hypothesize that a methyl group of FAD is oxidized to a formyl group. The significance of this not previously reported oxidation and the exceptionally high rate of oxygen reduction are discussed in relation to other flavin modifications and the possible occurrence of enzymes with similar properties.

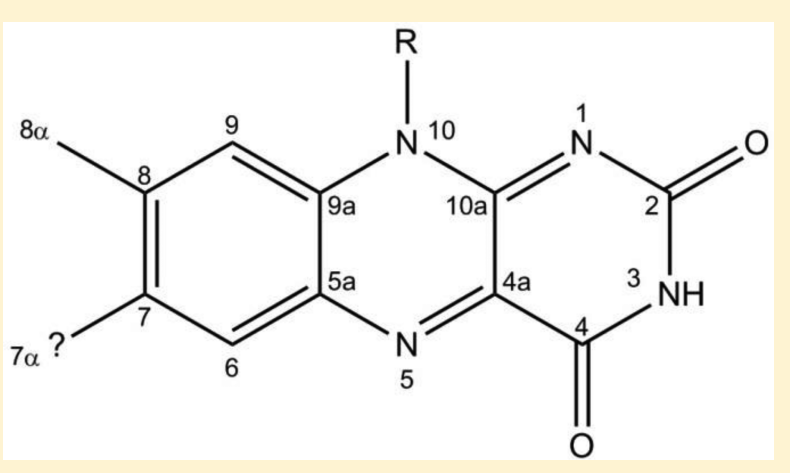

$\mathrm{T}$ hioredoxin ( $\operatorname{Trx}$ ) is a ubiquitous $12 \mathrm{kDa}$ dithiol protein regulating the cellular redox environment and providing reducing equivalents to enzymes like ribonucleotide reductase, peroxiredoxin, and methionine sulfoxide reductase, which employ redox-active cysteine residues in catalysis. After oxidation to the disulfide, Trx is recycled to the dithiol form by nicotinamide adenine dinucleotide phosphate (NADPH)dependent thioredoxin reductase (TrxR, also termed NTR). TrxR and Trx together constitute the Trx system. ${ }^{1}$

All known TrxRs are homodimers and carry one molecule of $\mathrm{FAD}$ per monomer but are divided into two types with distinctly different structures and molecular mechanisms. The high-molecular weight (HMW) TrxRs from, e.g., mammals, dipteran insects, and protozoan parasites and the low-molecular weight (LMW) TrxRs from bacteria, fungi, and plants have subunits of $\sim 55$ and $\sim 35 \mathrm{kDa}$, respectively. Both types of TrxR, like other flavoenzymes, can produce hydrogen peroxide upon reaction with molecular oxygen $\left(\mathrm{O}_{2}\right)$, a hazardous side reaction probably generally suppressed during evolution, except in cases of dedicated enzymes like macrophage $\mathrm{NADPH}$ oxidase that has a role in combating infections. ${ }^{2}$
HMW TrxR is similar in sequence to glutathione reductase (GR) and displays a similar mechanism of transfer of reducing equivalents that involves interfaces between monomers and domains. ${ }^{3}$ The hydride from NADPH is delivered to the $r e$ face of $\mathrm{FAD}$ and leaves the opposite $s i$ face to reduce the pair of redox-active cysteines within a conserved motif (CVNVGC), assisted by a histidine residue from the other subunit. A distinguishing feature between HMW TrxR and GR is the Cterminal extension of a flexible segment (of $\sim 15$ residues) having an additional redox center that shuttles reducing equivalents from the internal redox-active cysteines near the FAD to Trx. ${ }^{4}$ In HMW TrxRs from mammals, this additional redox center is a selenosulfide pair, but organisms such as Drosophila melanogaster instead have a second redox-active disulfide that intriguingly works with a similar efficiency. ${ }^{5}$ Several structures of HMW TrxRs are available as well as complexes with Trx. ${ }^{6,7}$

Received: November 3, 2014

Revised: February 6, 2015 
LMW TrxRs by contrast undergo a large conformational change allowing the transfer of electrons to Trx. ${ }^{8}$ The two FAD domains are central for LMW TrxR dimer formation and keep their relative positions, while the $\mathrm{NADPH}$ domains rotate, with respect to the $\mathrm{FAD}$ domains, by $66^{\circ}$ to switch between the flavin-oxidizing (FO) and flavin-reducing (FR) conformations in the catalytic cycle. In the FO conformation, the FAD and the redox-active disulfide are buried and positioned for internal electron transfer (from the re face of FAD), which excludes both thioredoxin and NADPH from productive interaction. In the more open FR conformation, the re face of FAD is exposed for the delivery of hydride from $\mathrm{NADPH}$ and the active site cysteines are exposed for interaction with Trx. Reducing equivalents thus enter and leave $\mathrm{FAD}$ at the same face. $\mathrm{A}$ nearby aspartic acid residue $\left(\mathrm{CA}^{\mathrm{T}} /{ }_{\mathrm{V}} \mathrm{CD}\right)$ assists the thioldisulfide exchange with Trx. ${ }^{9,10}$ The differences in mechanisms between the HMW and LMW types of enzymes make bacterial TrxR a promising target for new antimicrobial drugs. ${ }^{11-13}$

There is substantial structural information about LMW TrxRs from several eubacterial species, including a crystal structure of TrxR from Helicobacter pylori in reduced form at an excellent resolution of $1.45 \AA^{14}$ In addition, TrxR structures were determined from archea, yeast, plants, and a unicellular eukaryote. The FR conformation, however, has so far only been observed for Escherichia coli TrxR (EcTrxR), in a structure of the complex with Trx, stabilized by an intermolecular disulfide bond formed using single-active site cysteine mutants. ${ }^{8,15,16}$ Stopped-flow analysis of EcTrxR with NADPH conducted under anaerobic conditions at $1{ }^{\circ} \mathrm{C}$ demonstrated that the reductive half-reaction is very fast. ${ }^{17}$ Although the oxidative half-reaction is slower, it is the rearrangement between the FO and FR conformations that appears to limit turnover. ${ }^{8}$

Lactococcus lactis is a model organism for lactic acid bacteria and industrially important as a starter culture in the dairy industry. Like many Gram-positive bacteria within the genera Bacillus, Staphylococcus, and Streptococcus, L. lactis lacks a glutathione biosynthesis system. L. lactis furthermore has no bacillithiol found in Bacillus species, Staphylococcus aureus, or Deinococcus radiodurans. ${ }^{18}$ Remarkably, the knockout mutant of $\operatorname{tr} x B$ (encodes TrxR) in L. lactis is viable with no special requirements for the growth medium, ${ }^{19}$ while the corresponding gene appears to be more or less essential in Bacillus subtilis and $S$. aureus. ${ }^{20,21}$ LlTrxR is an efficient reductant for three different redoxin substrates: LlTrxA, similar to the wellcharacterized Trx1 from E. coli (EcTrx1), with a WCGPC active site motif; LlTrxD having a WCGDC motif; and $\mathrm{LINrdH}^{22}$ The latter is a glutaredoxin-like protein providing electrons to ribonucleotide reductase class Ib. ${ }^{23,24}$ LITrxA appears to act as a general disulfide reductase, whereas LlTrxD seems to have more specialized functions, possibly including arsenate detoxification. ${ }^{25}$ In this study, comparison of the $L$. lactis and E. coli Trx systems showed that the activity of LlTrxR is unstable in vitro. Ambient light in the laboratory is sufficient to destroy the activity, which motivated the closer investigation of the nature of light inactivation. Native LlTrxR, protected from light, and a light-inactivated form both show a high rate of turnover with molecular oxygen $\left(\mathrm{O}_{2}\right)$ as the electron acceptor.

\section{EXPERIMENTAL PROCEDURES}

Protein Purification. The genetic constructs, growth conditions, and purification of recombinant His-tagged TrxRs and Trxs from E. coli and barley have been described previously. $^{26-28}$ LITrxA and LITrxR were prepared similarly also using the pET15a expression vector. ${ }^{22}$ Cultures producing EcTrxR and LlTrxR were incubated either overnight at $20{ }^{\circ} \mathrm{C}$ or for $6 \mathrm{~h}$ at $30^{\circ} \mathrm{C}$ following addition of IPTG $(0.1 \mathrm{mM})$. The cell pellet from a $1 \mathrm{~L}$ culture was resuspended in $20 \mathrm{~mL}$ of Bugbuster protein extraction reagent (Novagen) containing Benzonase nuclease (Merck) and supplemented with FAD (0.2 $\mathrm{mM}$ ). Without the FAD supplement, the occupancy of FAD in the preparations of EcTrxR and LlTrxR was $10-40 \%$ as judged from the comparison of the protein concentration and absorbance $(456 \mathrm{~nm})$. The extract was shaken slowly (30 min at room temperature). After centrifugation at $4{ }^{\circ} \mathrm{C}$, the supernatant was filtered (pore size of $0.45 \mu \mathrm{m}$ ) and applied to a $5 \mathrm{~mL}$ HisTrap column (GE Healthcare) equilibrated with loading buffer $[20 \mathrm{mM}$ potassium phosphate ( $\mathrm{pH} 7.4), 500$ $\mathrm{mM} \mathrm{NaCl}$, and $10 \mathrm{mM}$ imidazole]. The column was washed with 2 column volumes of loading buffer with $50 \mathrm{mM}$ imidazole. Finally, the TrxRs were eluted by a linear gradient of 50 to $200 \mathrm{mM}$ imidazole in loading buffer. Yellow fractions were pooled, dialyzed [6-8 molecular weight cutoff (MWCO), Spectra/Por 1] against $0.1 \mathrm{M}$ potassium phosphate $(\mathrm{pH} 7.4)$ and $1 \mathrm{mM}$ EDTA, and concentrated to at least $5 \mathrm{mg} / \mathrm{mL}$ in a volume of $\leq 5 \mathrm{~mL}$ (Ultra-15 $10 \mathrm{kDa}$ MWCO, Amicon). Protein samples were stored at $-80{ }^{\circ} \mathrm{C}$ in aliquots. The yields of protein were higher for the TrxRs ( $>50 \mathrm{mg} / \mathrm{L}$ culture) than for the Trxs.

Spectrophotometric Analysis of Enzyme and Cofactor. Absorption spectra of oxidized TrxRs (300-600 nm) were routinely recorded (Ultrospec 2100 pro, Amersham Biosciences). The $\varepsilon_{456}$ of FAD in EcTrxR determined to be $11300 \mathrm{M}^{-1}$ $\mathrm{cm}^{-1}$ and equal to that of free FAD at $450 \mathrm{~nm}^{29}$ was used for quantification of FAD in LlTrxR both before (456 nm) and after light inactivation (445 nm) as well as for isolated lightdamaged cofactor ( $445 \mathrm{~nm}$ ). FAD occupancy was assessed by comparison to the protein concentration determined by the aid of amino acid analysis after hydrolysis for $24 \mathrm{~h}$ in $6 \mathrm{M} \mathrm{HCl}^{30}$ Fluorescence emission spectra of $5.0 \mu \mathrm{M}$ LlTrxR or EcTrxR were recorded (PerkinElmer luminescence spectrometer LS55). Excitation and emission wavelengths (10 nm slit widths) were 450 and 470-700 nm, respectively.

Measurement of TrxR Activity. LlTrxR, EcTrxR, and HvNTR2 were assayed in a $1 \mathrm{~mL}$ format at $2.0 \mu \mathrm{M}$ LlTrxA, EcTrx1, and barley HvTrx1, respectively, close to the experimentally determined $K_{\mathrm{M}}$ values of $3.5,2.2$, and $1.2 \mu \mathrm{M}$, respectively. $^{22,31}$ The assay mixture contained $0.2 \mathrm{mM} \mathrm{NADPH}$ with $0.2 \mathrm{mM}$ DTNB as the final electron acceptor in $0.1 \mathrm{M}$ potassium phosphate ( $\mathrm{pH} 7.5$ ), $2 \mathrm{mM}$ EDTA, and $0.1 \mathrm{mg} / \mathrm{mL}$ BSA, and reactions were started by the addition of TrxR to a final concentration of $20 \mathrm{nM}$. The formation of TNB anion was measured at $412 \mathrm{~nm}\left(\varepsilon_{412}=13600 \mathrm{M}^{-1} \mathrm{~cm}^{-1}\right)$.

Activity of LlTrxR and EcTrxR was also measured as described above but in the absence of Trx and DTNB, forcing the enzymes to use $\mathrm{O}_{2}$ as an electron acceptor, termed the $\mathrm{NADPH} / \mathrm{O}_{2}$ assay. The oxidation of $\mathrm{NADPH}$ was recorded at $340 \mathrm{~nm}\left(\varepsilon_{340}=6220 \mathrm{M}^{-1} \mathrm{~cm}^{-1}\right)$, and the concentration of TrxR was varied between 50 and $200 \mathrm{nM}$ to obtain a turnover number. The two TrxRs were also compared with respect to the use of $40 \mu \mathrm{M}$ dichlorophenolindophenol (DCPIP) as an unspecific electron acceptor monitoring the disappearance of absorbance at $600 \mathrm{~nm}\left(\varepsilon_{600}=20000 \mathrm{M}^{-1} \mathrm{~cm}^{-1}\right)$ at a TrxR concentration of $100 \mathrm{nM}$.

Conditions for Light Inactivation. The standard buffer during light incubations contained $0.1 \mathrm{M}$ potassium phosphate (pH 7.5), $2 \mathrm{mM}$ EDTA, $0.1 \mathrm{mg} / \mathrm{mL}$ BSA, and $2.0 \mu \mathrm{M}$ TrxR in 
an Eppendorf tube kept $20 \mathrm{~cm}$ below a 1225 Lumen $(21 \mathrm{~W}$ ) lamp in the cold room $\left(4{ }^{\circ} \mathrm{C}\right)$. According to the manufacturer Leuci (Relco group), the color temperature is $6500 \mathrm{~K}$ corresponding to a $\lambda_{\max }$ of $460 \mathrm{~nm}$. Samples $(10 \mu \mathrm{L})$ were withdrawn at intervals during the inactivation and assayed after dilution to $1 \mathrm{~mL}$ in standard buffer (to obtain a final TrxR concentration of $20 \mathrm{nM}$ ). The LlTrxR concentration was varied $(2.0-40 \mu \mathrm{M})$ in separate experiments with intermediate dilutions to achieve a concentration of $20 \mathrm{nM}$ in the assay. Overnight exposure for preparative-scale formation of lightdamaged enzyme was performed at 50-200 $\mu \mathrm{M}$ LlTrxR. To study the influence of $\mathrm{pH}$ on the light inactivation process, samples contained the standard components $(2.0 \mu \mathrm{M}$ LlTrxR, 2 $\mathrm{mM}$ EDTA, and $0.1 \mathrm{mg} / \mathrm{mL}$ BSA), but the major buffering component of the standard buffer $[0.1 \mathrm{M}$ potassium phosphate $(\mathrm{pH} 7.5)]$ was replaced with potassium acetate, adjusted by acetic acid at $\mathrm{pH} 4.0$ and 5.0, a mix of monobasic and dibasic potassium phosphate at $\mathrm{pH}$ 6.0, 7.0, and 8.0, and bicine adjusted with $\mathrm{NaOH}$ at $\mathrm{pH} 9.0$.

The influence of dissolved molecular oxygen $\left(\mathrm{O}_{2}\right)$ on light inactivation was probed using an $\mathrm{O}_{2}$ scavenging system in the standard buffer consisting of $10 \mathrm{mM}$ glucose, glucose oxidase from Aspergillus niger $(0.1 \mathrm{mg} / \mathrm{mL})$, and bovine catalase $(0.2$ $\mathrm{mg} / \mathrm{mL}$ ). Glucose was omitted from the control sample. The influence of iodide ions was tested by including potassium iodide $(0.1 \mathrm{M} \mathrm{KI})$ in the standard buffer. As a reference, potassium chloride $(0.1 \mathrm{M} \mathrm{KCl})$ was included in the standard buffer to account for the increased ionic strength.

Reconstitution of Light-Treated LITrxR. To LlTrxR (20 $\mu \mathrm{M}$ in $1 \mathrm{~mL}$ ) exposed to light treatment for $3 \mathrm{~h}$ under standard conditions as described above (and a light-protected control) was added a large excess of FAD $(8 \mathrm{mM}$ in $1.5 \mathrm{~mL})$. Subsequently, guanidinium chloride $(\mathrm{GdmCl})$ was gradually added to a final concentration of 2 or $3 \mathrm{M}$ followed by incubation for $21 \mathrm{~h}$ with gentle shaking at $4{ }^{\circ} \mathrm{C}$. The samples were then diluted in $0.1 \mathrm{M}$ potassium phosphate ( $\mathrm{pH} 7.5$ ), 2 $\mathrm{mM}$ EDTA, and $0.1 \mathrm{mg} / \mathrm{mL}$ BSA in several steps to reach $\mathrm{GdmCl}$ concentrations of $1,0.5$, and $0.1 \mathrm{M}$ followed by incubations for $18,1.5$, and $3 \mathrm{~h}$, respectively, at $4{ }^{\circ} \mathrm{C}$. The samples were then concentrated to $1 \mathrm{~mL}$ by ultrafiltration (Ultra-15 $10 \mathrm{kDa}$ MWCO, Amicon), loaded on a PD-10 column, and further concentrated (Ultra-0.5 $10 \mathrm{kDa}$ MWCO, Amicon) to a final volume of $0.5 \mathrm{~mL}$. The TrxR activity of the samples before and after reconstitution was analyzed as described above and compared to controls incubated without $\mathrm{GdmCl}$.

Heat Extraction of the Light-Damaged Cofactor. A LlTrxR sample $(190 \mu \mathrm{M})$ was exposed for $16 \mathrm{~h}$ under standard conditions for light inactivation (see above) and inspected for the resulting spectrum to show the typical appearance of light damage. The buffer was exchanged by loading the sample $(0.8$ $\mathrm{mL}$ ) on a PD10 column equilibrated in $62 \mathrm{mM}$ ammonium acetate $(\mathrm{pH}$ 6.6). Protein from the recovered fractions was incubated at $75{ }^{\circ} \mathrm{C}$ over $20 \mathrm{~min}$, resulting in a large precipitate. After centrifugation, the supernatant was loaded on an ultrafiltration device (Ultra-0.5, Ultracel-10 Membrane, Amicon) and the permeate was retained.

Mass Spectrometric Analysis of FADs. Undamaged and light-damaged $\mathrm{FAD}$ was analyzed by high-resolution mass spectrometry (HRMS) on a maXis G3 quadrupole time-offlight (qTOF) mass spectrometer (Bruker Daltonics), equipped with an electrospray ionization (ESI) source and connected to an Ultimate 3000 ultra-high-performance liquid chromatog- raphy (UPHLC) system with a UV/vis diode array detector (Dionex) and a Kinetex $2.6 \mu \mathrm{m}$ pentafluorophenyl (PFP), 100 $\mathrm{mm} \times 2.1 \mathrm{~mm}$ column (Phenomenex, Torrance, CA) maintained at $40{ }^{\circ} \mathrm{C}$. A linear $20 \mathrm{~min}, 0$ to $100 \%$ gradient from $20 \mathrm{mM}$ aqueous formic acid to $20 \mathrm{mM}$ formic acid in acetonitrile at a rate of $0.4 \mathrm{~mL} / \mathrm{min}$ was used, followed by isocratic elution for $3 \mathrm{~min}$. HRMS was performed in both negative $\left(\mathrm{ESI}^{-}\right)$and positive $\left(\mathrm{ESI}^{+}\right)$ion mode with a data acquisition range of 10 scans per second at $\mathrm{m} / z$ 100-1000. Sodium formate was automatically infused before each run and provided a mass accuracy of $<1.5 \mathrm{ppm}$. MS/MS was performed at 20 and $40 \mathrm{eV}$ for both $\mathrm{ESI}^{+}$and $\mathrm{ESI}^{-}$.

Ion-pair UHPLC-MS/MS analysis was conducted using an Agilent 1290 binary UHPLC system coupled with an Agilent 6460 triple quadrupole instrument equipped with an ESI source and operated in negative mode. Nitrogen was used as the collision gas at $30 \mathrm{eV}$. Separation was performed on an Agilent Poroshell phenyl column using a $10 \mathrm{mM}$ tributylamine, $10 \mathrm{mM}$ acetic acid ( $\mathrm{pH} 5.5$ ), and $90 \%$ methanol gradient system as described in detail by Magdenoska et al. ${ }^{32}$

Reactions with Dinitrophenylhydrazine (DNPH). Lightinactivated, heat-extracted $40 \mu \mathrm{M}$ FAD was incubated at room temperature with $80 \mu \mathrm{M}$ DNPH (total volume of $200 \mu \mathrm{L}$ ) in 10 $\mathrm{mM}$ phosphoric acid to give $\mathrm{pH}$ values of 3.0-3.5. Extracted FAD from untreated LlTrxR and EcTrxR was used as a reference. Cinnamaldehyde $(40 \mu \mathrm{M})$ was used as a positive control. Blanks containing the compounds described above but no DNPH were incubated in parallel. After 3 days in the dark at room temperature, precipates in samples were visually inspected.

Analysis of Ligand Binding in Three-Dimensional Structures of TrxR. The interactions between FAD and polypeptides in TrxRs were examined by the tool PDBsum (http://www.ebi.ac.uk/thornton-srv/databases/pdbsum), Ligand Explorer (http://www.rcsb.org/pdb/home/home.do), and Pymol.

\section{RESULTS}

LITrxR Is Light-Sensitive. The thoroughly studied E. coli Trx system (EcTrxR/EcTrxl) was used as a point of reference in the characterization of L. lactis TrxR. The E. coli system was subjected to steady state kinetics, and the saturation curve with EcTrx1 as the substrate for EcTrxR generated a $k_{\text {cat }}$ of $25 \mathrm{~s}^{-1}$ and a $K_{\mathrm{M}}$ of $2.5 \mu \mathrm{M}$, in agreement with the parameters reported in the literature. ${ }^{17,33}$ The L. lactis system (LlTrxR/LlTrxA), however, showed an approximately 10 -fold lower $k_{\text {cat }}$. It was noticed that the activity of fresh preparations was higher but decayed considerably upon storage for a few hours on ice. After various principal issues such as the integrity of the DNA clone and the solubility and stability of the enzyme had been interrogated, it became evident that LlTrxR is light-sensitive. The problem of inactivation was solved by avoiding daylight exposure and storing LlTrxR in brown tubes. Light-protected LlTrxR with LlTrxA as a substrate thus yielded a $k_{\text {cat }}$ of $\sim 26 \mathrm{~s}^{-1}$, essentially identical to that of the corresponding E. coli system.

The susceptibilities of LlTrxR, EcTrxR, and barley TrxR (HvNTR2) to light inactivation were compared. A compact fluorescent lamp ( $\lambda_{\max }=460 \mathrm{~nm}$, i.e., blue light $)$ situated in the cold room was used as the standard condition for light inactivation, and after incubation for $4 \mathrm{~h}$, EcTrxR and HvNTR2 retained $>70 \%$ activity using their cognate $\operatorname{Trx}$ acceptors (EcTrx1 and HvTrxh1) while LlTrxR retained $<4 \%$ activity (Figure 1). In the dark, all three enzymes retained $>90 \%$ 


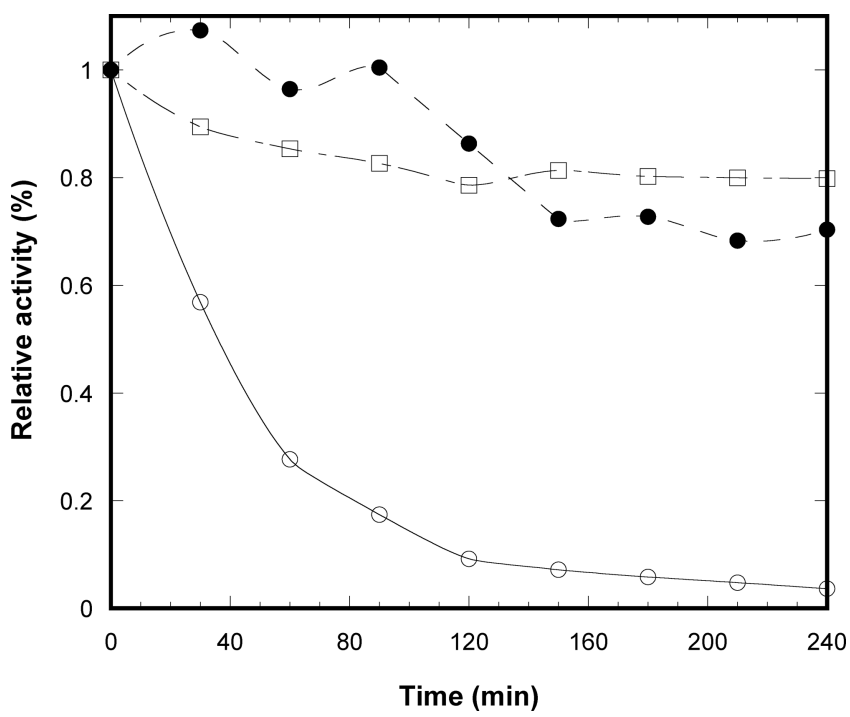

Figure 1. Inactivation of TrxR from L. lactis, E. coli, and Hordeum vulgare (HvNTR2) at pH 7.5. Samples at $2.0 \mu \mathrm{M} \operatorname{LlTrxR}(\mathrm{O}), \mathrm{EcTrxR}$ $(\bullet)$, and HvNTR2 ( $\square$ ) were exposed to light under standard conditions $(20 \mathrm{~cm}$ below a $21 \mathrm{~W}$ lamp with a maximal intensity at 460 $\mathrm{nm})$. Samples were withdrawn over $4 \mathrm{~h}$ and directly assayed together with their cognate Trx. The activities at different time points relative to the initial activity before light exposure are shown.

activity. Inactivation curves of LlTrxR repeated on four separate occasions indicated a half-life of $\sim 35 \mathrm{~min}$ (Figure $\mathrm{S} 1$ of the Supporting Information), and a very low level of residual activity $(0.2 \%)$ was determined after $16 \mathrm{~h}$. Inactivation of $2-40$ $\mu \mathrm{M}$ LlTrxR (Figure S2 of the Supporting Information) showed that only the highest concentrations $(20$ and $40 \mu \mathrm{M})$ provided significant protection.

Light-Damaged LITrxR Shows a Distinctly Changed Flavin Spectrum. Spectrophotometric analysis revealed that light inactivation is accompanied by major spectral changes in LlTrxR (Figure 2). The spectra of a $40 \mu \mathrm{M}$ sample of LlTrxR displayed large changes in three regions after illumination for 3 h. The main peak (1), giving rise to the yellow color, was blueshifted from $\sim 455$ to $\sim 445 \mathrm{~nm}$ but retained a slight shoulder toward higher wavelengths (465-475 $\mathrm{nm}$ in undamaged LlTrxR). The magnitude of the second peak (2), around 380 $\mathrm{nm}$, decreased. Finally, a large increase at 300-330 nm (3) not extending to the maximal absorbance at $260-270 \mathrm{~nm}$ (Figure S3 of the Supporting Information) where the adenosine moiety contributes. Additional spectra from the experiment showed a reinforcement of the described spectral features and a negligible degree of light scattering (Figure S4 of the Supporting Information). The presence of isosbestic points, e.g., at 400 $\mathrm{nm}$, suggests that light damage involves direct conversion to a photoproduct without observable intermediates. The maintained maximal absorbance at $445 \mathrm{~nm}$ indicates a very low level of photodestruction of the isoalloxazine ring system (Figure S4 of the Supporting Information). Consistent with the spectral characteristics of oxidized flavin, diffuse daylight from a window was very harmful, while standard "warm-white" bulbs (typical $\lambda_{\max }$ values of $>1000 \mathrm{~nm}$ ) shifted the spectrum only slowly. EcTrxR and free FAD used as reference substances for these initial spectral observations were insensitive to light (data not shown).

The fluorescence emission of the flavin bound to LlTrxR was 3-fold higher than that of EcTrxR before inactivation (Figure

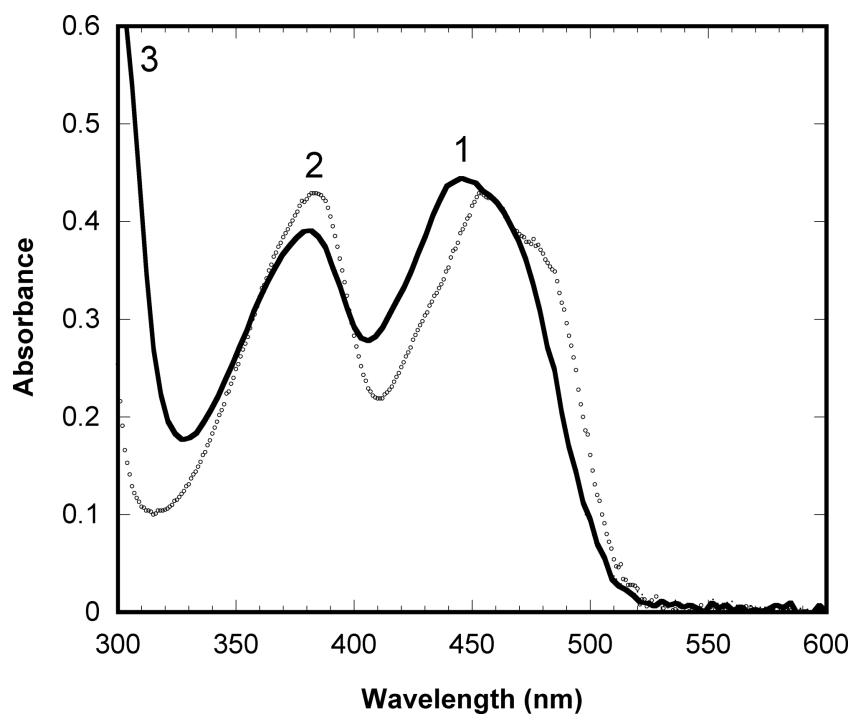

Figure 2. Spectral shift of LlTrxR upon light treatment. The spectrum between 300 and $600 \mathrm{~nm}$ of LlTrxR $(40 \mu \mathrm{M})$ is shown before (small empty cicles) and after $3 \mathrm{~h}$ (solid line) of exposure under the $21 \mathrm{~W}$ lamp. Three major changes $(1-3)$ are indicated: a blue shift of the main peak (1), a suppression of the second peak (2), and an increase in absorbance below $330 \mathrm{~nm}$ (3). Spectra of $10 \mu \mathrm{M}$ LlTrxR to display the region at $250-300 \mathrm{~nm}$ are shown in Figure S3 of the Supporting Information. Additional spectra of time points from this experiment are shown in Figure S4 of the Supporting Information.

S5 of the Supporting Information). This difference in quantum yield between the two enzymes suggests that the isoalloxazine ring is less rigidly fixed in LlTrxR ${ }^{34}$ After light exposure of LlTrxR, the emission intensity decreased to a level slightly lower than that of EcTrxR, and the maximal emission showed a small shift from 515 to $510 \mathrm{~nm}$. These properties of EcTrxR were not affected by light treatment (Figure S5 of the Supporting Information).

Analysis of LlTrxR by reducing sodium dodecyl sulfatepolyacrylamide gel electrophoresis revealed a band of apparent cross-linked dimer that increased in intensity after light inactivation. More than $95 \%$ of light-inactivated LlTrxR, however, appeared in the monomeric form (data not shown). Inactivated LlTrxR was subjected to trypsin digestion, but subsequent analysis by matrix-assisted laser desorption ionization time-of-flight MS did not reveal any differences in the peptide profile compared to that of a sample not exposed to light.

Addition of a large excess of exogenous FAD to lightdamaged LlTrxR in the presence of $2-3 \mathrm{M} \mathrm{GdmCl}$ (see Experimental Procedures for details) resulted in increased activity from approximately 7 to $40 \%$ relative to the level prior to inactivation. No increase in activity was observed after reconstitution of light-protected samples.

Taken together, these observations indicate that light inactivation is accompanied by structural changes in the tightly bound flavin cofactor, but modification on the protein level cannot be excluded.

The Rate of Light Inactivation Is Affected by $\mathrm{pH}$, Oxygen Concentration, and the Presence of lodide lons. LlTrxR was subjected to light inactivation in buffers with a range of different $\mathrm{pH}$ values. At $\mathrm{pH} 4.0$ and 9.0, activity declined already prior to light exposure [time zero (Figure 3)], suggesting that the enzyme is destabilized. The lowest $\mathrm{pH}$ 


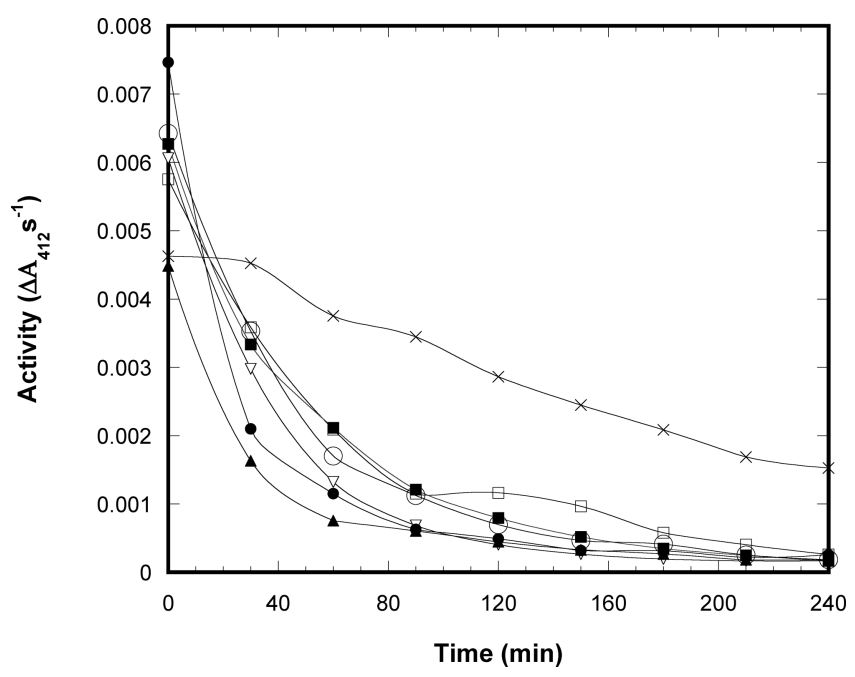

Figure 3. Dependence of $\mathrm{pH}$ on light inactivation. LlTrxR was diluted to $2.0 \mu \mathrm{M}$ in buffers in the $\mathrm{pH}$ range from 4.0 to 9.0 , and samples were removed over a $4 \mathrm{~h}$ light inactivation period for activity measurements with LITrxA as the substrate and DTNB as the final electron acceptor. Symbols used for the pH buffers: $(\times)$ 4.0, ( $\square$ ) 5.0, (ם) 6.0, ( $\nabla)$ 7.0,

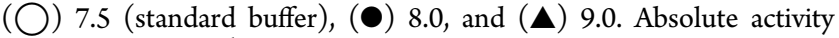
values, in $\Delta A_{412} \mathrm{~s}^{-1}$, are shown.

(4.0), however, conferred a strong protective effect against light inactivation possibly because of non-native conformations of LlTrxR in the vicinity of the flavin. At $\mathrm{pH} \mathrm{9.0,} \mathrm{inactivation} \mathrm{is}$ clearly faster than at the standard $\mathrm{pH}$ of 7.5. A mechanism of breakdown initiated by hydroxylation similar to what is observed for riboflavin analogues at alkaline $\mathrm{pH}$ may take place if a hydroxide ion can be stabilized in the vicinity of the flavin. ${ }^{35}$ However, the moderate increase in the rate of inactivation above $\mathrm{pH} 7.5$ does not suggest that hydrolysis is involved in the light inactivation process.

The $\mathrm{O}_{2}$ concentration in the inactivation buffer was lowered by addition of glucose, glucose oxidase, and catalase. The scavenging system was validated by a $>10$-fold decreased activity of LlTrxR in the $\mathrm{NADPH} / \mathrm{O}_{2}$ assay, likely explained by a correspondingly decreased amount of dissolved $\mathrm{O}_{2}$. The scavenging system strongly slowed the inactivation (Figure 4), suggesting the involvement of $\mathrm{O}_{2}$. Next, addition of potassium iodide, a quencher of photoexcited triplet state flavins, was investigated. Indeed, iodide has a protective effect at least as strong as that caused by a lowered $\mathrm{O}_{2}$ content (Figure 5). To account for the additional ionic strength, potassium chloride was included in the reference sample.

The influence of LlTrxA and LINrdH $(1 \mu \mathrm{M})$, superoxide dismutase $(0.02$ and $0.1 \mathrm{mg} / \mathrm{mL}), \mathrm{FAD}$ and riboflavin $(20 \mu \mathrm{M})$, DTT $(2 \mathrm{mM})$, and tryptophan $(1 \mathrm{mM})$ as additives was tested separately using a $2 \mathrm{~h}$ illumination. Only riboflavin and FAD offered minor protection, albeit less than the $\mathrm{O}_{2}$-scavenging system. No effect on inactivation was obtained by removing 2 mM EDTA (often employed at a higher concentration in anaerobic photoreduction) $)^{36}$ from LlTrxR by gel filtration. These various findings suggested the involvement of molecular oxygen $\left(\mathrm{O}_{2}\right)$ and photoexcited $\mathrm{FAD}$ in the process of inactivation.

LITrxR Reduces Molecular Oxygen $\left(\mathrm{O}_{2}\right)$ Faster Than EcTrxR. EcTrxR is the most well-characterized LMW TrxR, and its sequence is $37 \%$ identical to that of LlTrxR. These two TrxRs displayed similar $k_{\text {cat }}$ values when they were assayed with their cognate Trx, and DTNB as the final electron acceptor.

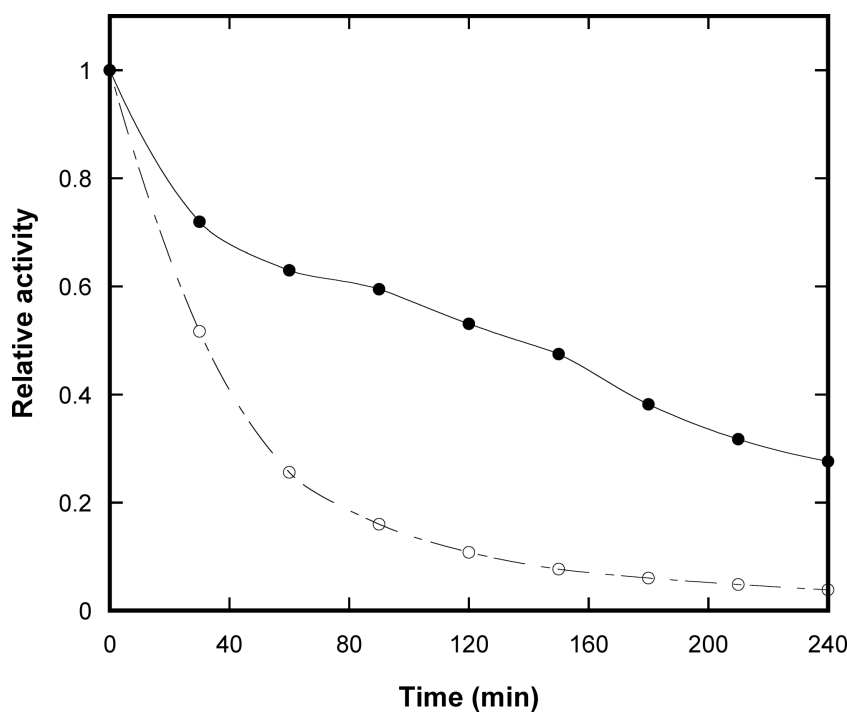

Figure 4. Influence of $\mathrm{O}_{2}$ on light inactivation. LlTrxR was diluted to $2.0 \mu \mathrm{M}$ in standard buffer supplemented with glucose oxidase and catalase $(0.05$ and $0.2 \mathrm{mg} / \mathrm{mL}$, respectively). Glucose $(10 \mathrm{mM})$ was added to activate the enzymatic system for removal of $\mathrm{O}_{2}$ and $\mathrm{H}_{2} \mathrm{O}_{2}$ $(\boldsymbol{O})$ and a control without glucose $(\mathrm{O})$. Samples were removed over a $4 \mathrm{~h}$ light inactivation period for activity measurements with LlTrxA as the substrate and DTNB as the final electron acceptor. The activities relative to the initial activity before light exposure are shown.

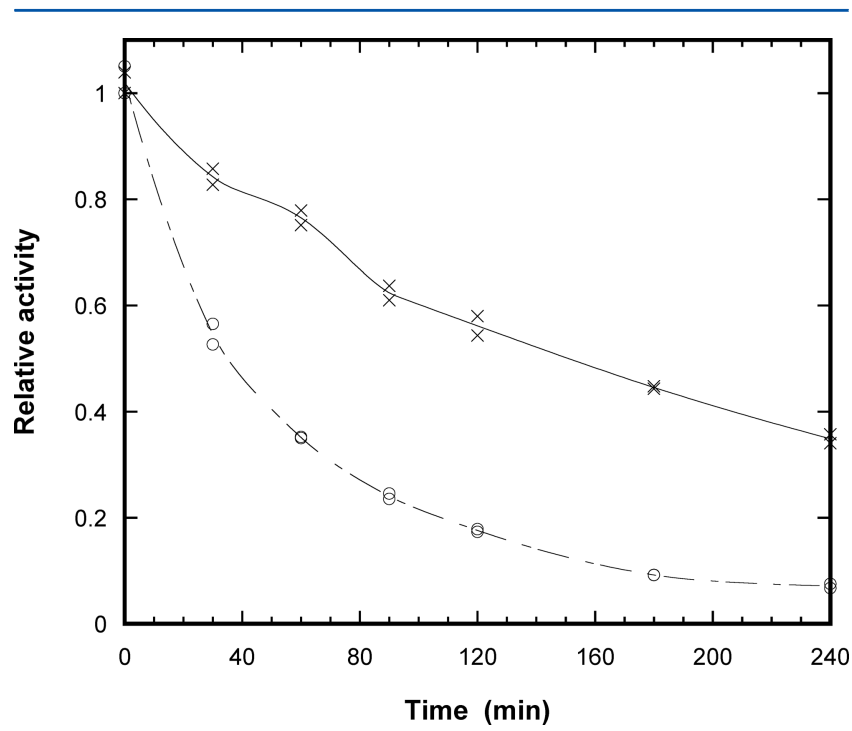

Figure 5. Influence of iodide ions on light inactivation. LlTrxR was diluted to $2.0 \mu \mathrm{M}$ in standard buffer supplemented with $0.1 \mathrm{M} \mathrm{KI}(\times)$ or in the control with $0.1 \mathrm{M} \mathrm{KCl}(\mathrm{O})$. Samples were removed over a 4 $\mathrm{h}$ light inactivation period for activity measurements with LlTrxA as the substrate and DTNB as the final electron acceptor. The activities relative to the initial activity before light exposure are shown.

EcTrxR displayed a turnover of $1.7 \mathrm{~s}^{-1}$ for reduction of the classical redox dye DCPIP, twice that of LlTrxR (data not shown). These results suggest that the two reduced TrxRs have somewhat different surface properties.

When assayed without an added electron acceptor, TrxR reduces $\mathrm{O}_{2}$ to $\mathrm{H}_{2} \mathrm{O}_{2}$ and LlTrxR showed a turnover of $0.33 \mathrm{~s}^{-1}$ in the NADPH/O $/ \mathrm{O}_{2}$ assay, 10-fold faster than that of EcTrxR (Figure. 5). Assuming the commonly accepted $\mathrm{O}_{2}$ concentration of $200 \mu \mathrm{M}$ in aqueous solutions, EcTrxR reduces $\mathrm{O}_{2}$ at a rate of $160 \mathrm{M}^{-1} \mathrm{~s}^{-1}$, i.e., slightly more slowly than free reduced 
flavin $\left(250 \mathrm{M}^{-1} \mathrm{~s}^{-1}\right){ }^{37}$ while the corresponding 10-fold higher rate for LlTrxR is $1600 \mathrm{M}^{-1} \mathrm{~s}^{-1}$. In comparison, flavindependent oxidases dedicated to the use of $\mathrm{O}_{2}$ typically reduce with much higher rate constants in the range of $10^{5}-10^{6} \mathrm{M}^{-1}$ $\mathrm{s}^{-1} \cdot{ }^{38,39}$ Light-inactivated LlTrxR with $<2 \%$ residual activity in the DTNB assay retained the high reduction rate of $\mathrm{O}_{2}$ as seen for the noninactivated enzyme. In fact, a slightly higher turnover of $0.4 \mathrm{~s}^{-1}$ was recorded, demonstrating that $\mathrm{NADPH}$ is able to reduce the light-inactivated enzyme. However, in the $\mathrm{NADPH} / \mathrm{O}_{2}$ assay, the reductive half-reaction is conceivably at least 2 orders of magnitude faster than the oxidative. ${ }^{17} \mathrm{~A}$ correspondingly large decrease in the reductive half-reaction can thus pass undetected in the assay.

Mass Spectrometric Analysis of the Light-Damaged FAD Suggests Aldehyde Formation. Flavins from both light-inactivated and untreated material were extracted by heat, with a recovery of $>50 \%$, suggesting that a majority of the cofactors are not covalently bound to the enzyme. Analysis of the extract from light-inactivated LlTrxR by UHPLC-ESI ${ }^{+}$HRMS revealed a major ion at $m / z 800.1433$ with an elution profile similar to that of the nonmodified flavin $(\mathrm{m} / z$ 786.1642) on a PFP column (Figure S6 of the Supporting Information). The mass difference $(m / z$ 13.979) unambiguously corresponds to the addition of one oxygen atom and the loss of two hydrogen atoms, consistent with conversion of a methyl group to an aldehyde. Furthermore, a minor ion at $\mathrm{m} / \mathrm{z} 816.1385$ indicated further oxidation of the aldehyde to a carboxylate group or, alternatively, but less likely, hydroxylation of a second methyl group (Figure S6 of the Supporting Information). The native and presumed aldehyde-modified forms of FAD were readily baseline separated by ion-pair chromatography, and the shorter retention time of the modified FAD is consistent with a higher polarity of the oxidized species. $\mathrm{ESI}^{+} \mathrm{MS} / \mathrm{MS}$ spectra of the presumed FAD aldehyde and the nonmodified flavin were highly similar and only displayed fragment ions originating from only the ribityl and phosphoadenosyl groups (data not shown). $\mathrm{ESI}^{-} \mathrm{MS} / \mathrm{MS}$ of the nonmodified flavin on the other hand showed a low-intensity ion at $\mathrm{m} / z 241.0729$ originating from the isoalloxazine ring system that was shifted up by $m / z$ 13.979 in the aldehyde form, suggesting that the site of modification is localized within this part of the FAD molecule (Figure S7 of the Supporting Information).

To consolidate the results of the mass spectrometric analysis, we probed the inactivated LlTrxR with DNPH that reacts with ketone and aldehyde groups to form insoluble derivatives. Brick-red precipitates appeared with FAD extracted from lightinactivated LlTrxR and cinnamaldehyde (the positive control), while precipitate was not observed with FAD extracted from EcTrxR or untreated LlTrxR. Although the precipitate was similar to the positive control, stoichiometric oxidation to an aldehyde cannot be concluded.

The two methyl groups defined as positions $7 \alpha$ and $8 \alpha$ on the isoalloxazine ring system are the possible sites of aldehyde formation. Oxidation of position $8 \alpha$ was previously observed in a flavoenzyme. ${ }^{40}$ In the $\mathrm{R} 268 \mathrm{~K}$ mutant of lactate oxidase from Aerococcus viridans, FMN was almost completely transformed into 8-formyl-FMN upon aging. However, the positional identification relied on the spectral properties being similar to those of the synthesized analogue 8-formyl tetraacetylriboflavin. ${ }^{41}$ Spectra of oxidized forms formylated at position $8 \alpha$ are different from the spectrum of the light-damaged $\mathrm{FAD}$ in LlTrxR (see Discussion). Edmondson ${ }^{41}$ showed that 8formylriboflavin forms a blue 8-formylflavin hydroquinione cation upon reduction by $\mathrm{TiCl}_{3}$ in $6 \mathrm{M} \mathrm{HCl}$, and the reaction does not require removal of $\mathrm{O}_{2}$. Incubating the extracted lightdamaged cofactor from LlTrxR under these conditions (a 5-fold excess of $\mathrm{TiCl}_{3}$ ) did not increase absorbance above $550 \mathrm{~nm}$, indicating that 8 -formyl-FAD is not a major constituent of the light-damaged FAD in LlTrxR.

\section{DISCUSSION}

Here we report on the surprising inactivation of LlTrxR by blue light under aerobic conditions, a phenomenon not reported for any other TrxR. In fact, light inactivation under these conditions is unusual or at least slow for other flavoenzymes. On the basis of the mass spectrometric analysis and a positive reaction with $\mathrm{DNPH}$, our results suggest generation of an aldehyde derived from a methyl group. Mass spectrometric fragmentation pinpointed the modification to be localized in the isoalloxazine ring, which has two methyl groups. Iodide seems to exert a protective effect by scavenging photoexcited $\mathrm{FAD}$. It appears likely that triplet state flavin formed upon photoexcitation reacts with $\mathrm{O}_{2}$, generating a reactive oxygen species $\left({ }^{1} \mathrm{O}_{2}\right.$ or $\left.\mathrm{O}_{2}{ }^{-}\right)$, which in turn attacks and oxidizes the methyl group to a formyl group. A modification of the methyl group at position $7 \alpha$ has, to the best of our knowledge, never been reported in a flavoenzyme, but it has been observed at the level of riboflavin. Yagi and co-workers thus isolated both $7 \alpha$ and $8 \alpha$-hydroxyriboflavin from urine and showed that liver microsomes catalyze this NADPH-dependent hydroxylation. $^{42,43}$

Modifications of position $8 \alpha$ are implicated in covalent attachment of flavins to some enzymes, e.g., succinate dehydrogenase and monoamine oxidase. ${ }^{44}$ The influence of these linkages on activity and redox potential has been studied using synthetic flavin analogues. ${ }^{45} 8$-Formyl-FAD, 8-formyltetraacetylriboflavin, and 8-formyl-FMN extracted from the aged R286K mutant of L-lactate oxidase show nearly identical spectral properties (in the range of $300-800 \mathrm{~nm}$ ). ${ }^{40,41,46}$ Like that of light-damaged LlTrxR, the spectrum of oxidized flavin with an 8-formyl substitution displays an elevated absorbance at $300 \mathrm{~nm}$ (Figure 2). Otherwise, the spectrum is very different; the main peak is red-shifted $(460 \mathrm{~nm})$ in contrast to the blueshift in light-damaged LlTrxR, and the second peak around 380 $\mathrm{nm}$ is elevated. These differences suggest that the aldehyde instead is formed at position $7 \alpha$, which is a testable hypothesis, and crystallization trials with the light-inactivated enzyme have been initiated. The strong negative effect on activity may be caused by changes in redox potential and/or positioning of redox-active flavin atoms (e.g., N5) hindering electron transfer to the dithiol motif. Experimental and theoretical work on 7,8substituted flavin analogues predicts increases in redox potentials of at least $50 \mathrm{mV} .^{47}$ The light-damaged enzyme is, however, still redox-active with $\mathrm{O}_{2}$.

Is there any biological significance of the deviating properties of LlTrxR? A naive idea is simply that L. lactis, which thrives at low levels of $\mathrm{O}_{2}$, uses light inactivation as a sensor of light and $\mathrm{O}_{2}$ with immediate effects on DNA replication via ribonucleotide reductase. There are several established examples of photoexcited flavoproteins that function as photoreceptors of blue light, ${ }^{48}$ for example, YtvA from B. subtilis. ${ }^{49}$ It could also be suggested that inactivation of TrxR results in an oxidized thiol redox environment that activates redox-sensitive transcription factors such as Spx. ${ }^{50}$ In general, blue light at wavelengths of $\leq 470 \mathrm{~nm}$ has an antibacterial effect. Optimal cell killing of $S$. aureus was found to occur at $405 \mathrm{~nm}$, and the mechanism has 
been proposed to involve photoexcitation of porphyrins, reaction with $\mathrm{O}_{2}$, and subsequent formation of reactive oxygen species. $^{51,52}$

LlTrxR showed a rate of $\mathrm{O}_{2}$ reduction 10 -fold higher than that of EcTrxR (Figure 6). Similar results were obtained with

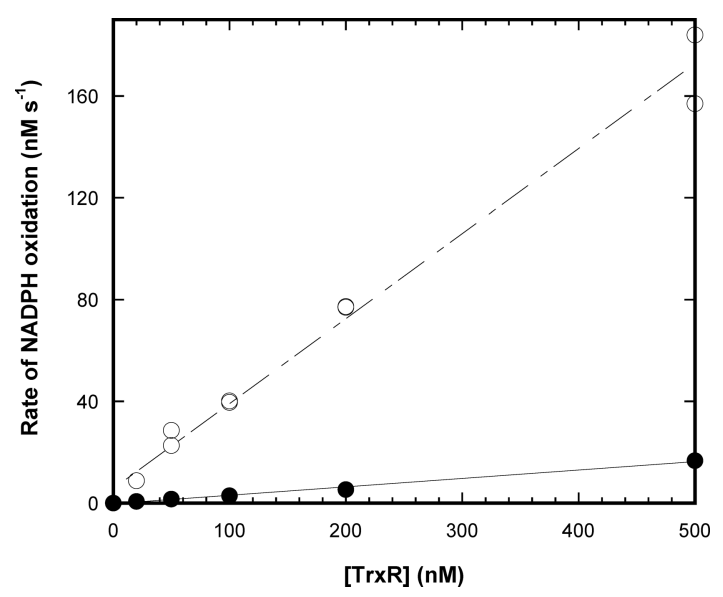

Figure 6. Oxidation of NADPH via TrxR using $\mathrm{O}_{2}$ as an electron acceptor. LlTrxR $(O)$ and $\operatorname{EcTrxR}(\bullet)$ were incubated in the presence of NADPH $(0.2 \mathrm{mM})$. A background rate of $0.00000762 \Delta A_{340} \mathrm{~s}^{-1}$, conceivably NADPH destruction, was subtracted from all rates, and the activity recorded $\left(\Delta A_{340} \mathrm{~s}^{-1}\right)$ was converted to nanomolar $\mathrm{NADPH}$ oxidized per second.

the flavoenzyme dihydroorotate dehydrogenase from E. coli and L. lactis, i.e., a 7-fold higher reduction rate for the L. lactis enzyme. ${ }^{53}$ During fermentative growth, L. lactis utilizes NADH oxidases to reduce $\mathrm{O}_{2}$ to restore the $\mathrm{NAD}^{+}$pool. These flavoenzymes display different mechanisms and release either $\mathrm{H}_{2} \mathrm{O}$ or $\mathrm{H}_{2} \mathrm{O}_{2}$ as main product of catalysis. ${ }^{54}$ Similar to many other lactic acid bacteria, L. lactis lacks catalase and relies on peroxiredoxins and $\mathrm{NADH}$ peroxidases to degrade $\mathrm{H}_{2} \mathrm{O}_{2}$. Strains of Streptococcus pneumoniae were shown to both tolerate and excrete $\mathrm{H}_{2} \mathrm{O}_{2}$, which has been suggested to be a strategy for outcompeting other microorganisms, possibly utilized widely among lactic acid bacteria. ${ }^{55,56}$ L. lactis contains a low number of enzymes with iron-sulfur clusters, generally sensitive to $\mathrm{H}_{2} \mathrm{O}_{2}$ and $\mathrm{O}_{2}^{-}$

Might other LMW TrxRs have the features shown here for LlTrxR, i.e., sensitivity to light and a high rate of $\mathrm{O}_{2}$ reduction? Both processes are oxidative; however, only the $\mathrm{O}_{2}$ reduction in the $\mathrm{NADPH} / \mathrm{O}_{2}$ assay is without doubt dependent on the fully reduced form, obtained by hydride transfer, while the comparatively slower light inactivation may involve a oneelectron-reduced species of FAD. Furthermore, the site of oxidative attack is probably different; we identified carbon $7 \alpha$ as a probable site for light inactivation, and the $\mathrm{C} 4 \mathrm{a}$ carbon is likely to be employed for $\mathrm{O}_{2}$ reduction. Both oxidases and hydroxylases, dedicated to the use of $\mathrm{O}_{2}$, employ $\mathrm{C} 4 \mathrm{a}-$ hydroperoxide intermediates in catalysis. ${ }^{2}$ Dehydrogenase flavoenzymes in contrast seem to have evolved toward low reactivity with $\mathrm{O}_{2}$, and reduction can be considered as an inappropriate side reaction. A113 on the re side of the C4a locus was identified as a gatekeeper for $\mathrm{O}_{2}$ reduction in $\mathrm{L}-$ galactono- $\gamma$-lactone dehydrogenase, and the corresponding A113G mutation, creating more free space above the locus, converted the enzyme to a catalytically competent oxidase. ${ }^{57} \mathrm{~A}$ change in the opposite direction, toward less reduction of $\mathrm{O}_{2}$, was achieved in lactate monooxygenase by a mutation that diminished the amount of free space above the C4a locus. ${ }^{58}$ TrxR structures in the FO conformation are defined by having the active site disulfide within 3.0-4.0 $\AA$ of C4a and N5, thus preventing access of $\mathrm{O}_{2}$. Exposure of the reactive locus, however, probably takes place during the switch between conformations and in the FR conformation without bound $\mathrm{NADPH}$ or $\mathrm{NADP}^{+}$. The structure of HvNTR2 shows a conformation between the FR and FO conformations, with the active site disulfide closer to carbon $7 \alpha .{ }^{59}$ Like EcTrxR, HvNTR2 shows a low rate of $\mathrm{O}_{2}$ reduction, observed as a background rate in measurements of insulin reduction by the barley Trxs. ${ }^{60}$ Apart from the accessibility of $\mathrm{O}_{2}$, stabilization of the activated oxygen species in the reaction intermediate greatly affects the rate, e.g., by a lysine residue, identified to be primarily responsible for stabilization of the transient negative charge on FAD C(4a)-hydroperoxide in sarcosine oxidase. ${ }^{2,61}$

At present, LMW TrxR structures in the FO conformation from 14 species are available in the Protein Data Bank (PDB). There are several interactions with $\mathrm{FAD}$, most of which concern the ribityl group, the two phosphate groups, and the adenosine moiety. With respect to polar interactions with the chemically active isoalloxazine ring, only two direct hydrogen bonds recur in all 14 structures. They involve $\mathrm{O} 2$ as the acceptor and $\mathrm{N} 3$ as the donor, respectively. The corresponding residues involved are the main chain $\mathrm{NH}$ group of a nonpolar residue $\left(\mathrm{A} 295_{\mathrm{EcTrxR}}\right)$ and a completely conserved Asn residue $\left(\mathrm{N} 51_{\mathrm{EcTrxR}}\right)$. These two hydrogen bonds, also seen in the FR conformation of EcTrxR, appear to be central to LMW TrxRs, certainly serving both to keep the ring system in position and to control its reactivity. Other residues surrounding the isoalloxazine ring show less conservation, as outlined below.

The enzyme from $S$. aureus (SaTrxR) is the closest homologue of LlTrxR with a determined structure (PDB entry 4GCM). The sequence identity is $53 \%$ (with no need for introducing gaps) in a pairwise alignment (Figure S8 of the Supporting Information). Five residues in SaTrxR (Q42, N45, T46, Y133, and D138) have atoms within $6.0 \AA$ of the $7 \alpha$ methyl carbon of FAD, and only one of them is completely conserved, D138, the active site acid/base corresponding to D 139 EcTrxR. Q42 $_{\text {SaTrxR }}$ (Q42 $2_{\text {EcTrxR }}$ ) is strongly conserved, although its substitution with alanine in Mycobacterium tuberculosis TrxR maintains a conserved hydrogen bond to a phosphate through its main chain $\mathrm{NH}$ group. ${ }^{62} \mathrm{~N} 45_{\text {SaTrxR }}$ and Y133 $3_{\text {SaTrxR }}$ occupy less conserved positions, while $T 46_{\text {SaTrxR }}$ is conserved with substitutions only with serine. These residues in SaTrxR are conserved in the TrxRs from L. lactis, Streptococcus mutans, and Bacillus anthracis (BaTrxR), which group together in the alignment (Figure S8 of the Supporting Information). BaTrxR has been thoroughly investigated, including spectral characterization, but no unexpected properties were reported. ${ }^{63}$

In comparison to EcTrxR, the $7 \alpha$-methyl carbon is buried less tightly in the SaTrxR structure; e.g., the distance to the phenolic oxygen atom of $\mathrm{Y} 118_{\mathrm{EcTrxR}}$ is $3.8 \AA$, while the closest atom (NZ) of the corresponding residue in SaTrxR, K117, is $7.6 \AA$ from the $7 \alpha$-methyl carbon. Moreover, Ala134 $4_{\mathrm{EcTrxR}}(\mathrm{CB})$ is positioned within $4.0 \AA$, while the corresponding residue Y133 $3_{\text {SaTrxR }}$ shows a closest distance of $5.4 \AA$ (ring carbon CD). This substitution is notable in a segment that is highly conserved in the context of the active site cysteines and acid/ base aspartate residue (SYYCAVCDG). Furthermore, these residues are displaced during the transition to the $F R$ conformation. Subtle differences related to the conformational 
change can make LlTrxR differently reactive with $\mathrm{O}_{2}$, and the structure of SaTrxR is not a sufficiently good model for making predictions about the mechanisms. However, we find it likely that TrxRs from more closely related genera, e.g., Streptococcus (with $\sim 70 \%$ sequence identity), display properties like those of LlTrxR.

\section{ASSOCIATED CONTENT}

\section{S Supporting Information}

Eight figures as indicated in the text. This material is available free of charge via the Internet at http://pubs.acs.org.

\section{AUTHOR INFORMATION}

\section{Corresponding Author}

*Telephone: +45 4525 5503. Fax: +45 4588 6307. E-mail: ph@ bio.dtu.dk.

\section{Funding}

The work was supported by the Danish Council for Technology and Production Sciences (FTP, Grant 274-080413) and the Carlsberg Foundation (Grant 2010_01-0098).

\section{Notes}

The authors declare no competing financial interest.

\section{ACKNOWLEDGMENTS}

We thank Dale Edmondson, Kaj Frank Jensen, and Peter Macheroux for sharing their experiences with flavins and flavoenzymes, Oskar Axelsson (Spago Nanomedical) for advice concerning the DNPH reaction, and Anita Iversen and Olivera Magdenoska for help with accurate HRMS and ion-pair UHPLC-MS/MS, respectively. Anne Blicher is thanked for performing amino acid analysis, and finally, we acknowledge Bo Svensson (Saromics Biostructure) for the inspection of the SaTrxR structure.

\section{ABBREVIATIONS}

DCPIP, dichlorophenolindophenol; DNPH, 2,4-dinitrophenylhydrazine; DTNB, 5,5'-dithiobis(2-nitrobenzoic acid); EcTrx1, E. coli Trx1; EcTrxR, E. coli TrxR; ESI, electrospray ionization; FO, flavin-oxidizing; FR, flavin-reducing; GR, glutathione reductase; HMW, high-molecular weight; HRMS, highresolution mass spectrometry; HvNTR2, thioredoxin reductase from barley; LlNrdH, L. lactis NrdH; LlTrxA, L. lactis TrxA; LlTrxD, L. lactis TrxD; LlTrxR, L. lactis TrxR; LMW, lowmolecular weight; MS, mass spectrometry; MS/MS, tandem MS; qTOF, quadrupole time-of-flight; TNB, 2-nitro-5thiobenzoate; Trx, thioredoxin; TrxR, NADPH-dependent thioredoxin reductase; UHPLC, ultra-high-performance liquid chromatography.

\section{REFERENCES}

(1) Arnér, E. S. J., and Holmgren, A. (2000) Physiological functions of thioredoxin and thioredoxin reductase. Eur. J. Biochem. 267, 61026109.

(2) Fagan, R. L., and Palfey, B. A. (2010) Flavin-Dependent Enzymes. In Comprehensive Natural Products II Chemistry and Biology (Mander, L., and Lui, H.-W., Eds.) pp 37-113, Elsevier, Oxford, U.K.

(3) Arscott, L. D., Gromer, S., Schirmer, R. H., Becker, K., and Williams, C. H., Jr. (1997) The mechanism of thioredoxin reductase from human placenta is similar to the mechanisms of lipoamide dehydrogenase and glutathione reductase and is distinct from the mechanism of thioredoxin reductase from Escherichia coli. Proc. Natl. Acad. Sci. U.S.A. 94, 3621-3626.
(4) Cheng, Q., Sandalova, T., Lindqvist, Y., and Arner, E. S. (2009) Crystal structure and catalysis of the selenoprotein thioredoxin reductase 1. J. Biol. Chem. 284, 3998-4008.

(5) Gromer, S., Johansson, L., Bauer, H., Arscott, L. D., Rauch, S., Ballou, D. P., Williams, C. H., Jr., Schirmer, R. H., and Arner, E. S. (2003) Active sites of thioredoxin reductases: Why selenoproteins? Proc. Natl. Acad. Sci. U.S.A. 100, 12618-12623.

(6) Fritz-Wolf, K., Kehr, S., Stumpf, M., Rahlfs, S., and Becker, K. (2011) Crystal structure of the human thioredoxin reductasethioredoxin complex. Nat. Commun. 2, 1-8.

(7) Fritz-Wolf, K., Urig, S., and Becker, K. (2007) The structure of human thioredoxin reductase 1 provides insights into $\mathrm{C}$-terminal rearrangements during catalysis. J. Mol. Biol. 370, 116-127.

(8) Lennon, B. W., Williams, C. H., and Ludwig, M. L. (2000) Twists in catalysis: Alternating conformations of Escherichia coli thioredoxin reductase. Science 289, 1190-1194.

(9) Mulrooney, S. B., and Williams, C. H. (1994) Potential active-site base of thioredoxin reductase from Escherichia coli: Examination of histidine 245 and aspartate 139 by site-directed mutagenesis. Biochemistry 33, 3148-3154.

(10) Oliveira, M. A., Discola, K. F., Alves, S. V., Medrano, F. J., Guimaraes, B. G., and Netto, L. E. (2010) Insights into the specificity of thioredoxin reductase-thioredoxin interactions. A structural and functional investigation of the yeast thioredoxin system. Biochemistry 49, 3317-3326.

(11) Koch, O., Jager, T., Heller, K., Khandavalli, P. C., Pretzel, J., Becker, K., Flohe, L., and Selzer, P. M. (2013) Identification of M. tuberculosis thioredoxin reductase inhibitors based on high-throughput docking using constraints. J. Med. Chem. 56, 4849-4859.

(12) Lu, J., and Holmgren, A. (2014) The thioredoxin antioxidant system. Free Radical Biol. Med. 66, 75-87.

(13) Lu, J., Vlamis-Gardikas, A., Kandasamy, K., Zhao, R., Gustafsson, T. N., Engstrand, L., Hoffner, S., Engman, L., and Holmgren, A. (2013) Inhibition of bacterial thioredoxin reductase: An antibiotic mechanism targeting bacteria lacking glutathione. FASEB J. 27, 13941403.

(14) Gustafsson, T. N., Sandalova, T., Lu, J., Holmgren, A., and Schneider, G. (2007) High-resolution structures of oxidized and reduced thioredoxin reductase from Helicobacter pylori. Acta Crystallogr. D63, 833-843.

(15) Veine, D. M., Mulrooney, S. B., Wang, P. F., and Williams, C. H. (1998) Formation and properties of mixed disulfides between thioredoxin reductase from Escherichia coli and thioredoxin: Evidence that cysteine- 138 functions to initiate dithiol-disulfide interchange and to accept the reducing equivalent from reduced flavin. Protein Sci. 7, $1441-1450$.

(16) Wang, P. F., Veine, D. M., Ahn, S. H., and Williams, C. H. (1996) A stable mixed disulfide between thioredoxin reductase and its substrate, thioredoxin: Preparation and characterization. Biochemistry $35,4812-4819$.

(17) Lennon, B. W., and Williams, C. H. (1997) Reductive halfreaction of thioredoxin reductase from Escherichia coli. Biochemistry 36, 9464-9477.

(18) Newton, G. L., Rawat, M., La Clair, J. J., Jothivasan, V. K., Budiarto, T., Hamilton, C. J., Claiborne, A., Helmann, J. D., and Fahey, R. C. (2009) Bacillithiol is an antioxidant thiol produced in Bacilli. Nat. Chem. Biol. 5, 625-627.

(19) Vido, K., Diemer, H., Van Dorsselaer, A., Leize, E., Juillard, V., Gruss, A., and Gaudu, P. (2005) Roles of thioredoxin reductase during the aerobic life of Lactococcus lactis. J. Bacteriol. 187, 601-610.

(20) Kobayashi, K., Ehrlich, S. D., Albertini, A., Amati, G., Andersen, K. K., Arnaud, M., Asai, K., Ashikaga, S., Aymerich, S., Bessieres, P., Boland, F., Brignell, S. C., Bron, S., Bunai, K., Chapuis, J., Christiansen, L. C., Danchin, A., Debarbouille, M., Dervyn, E., Deuerling, E., Devine, K., Devine, S. K., Dreesen, O., Errington, J., Fillinger, S., Foster, S. J., Fujita, Y., Galizzi, A., Gardan, R., Eschevins, C., Fukushima, T., Haga, K., Harwood, C. R., Hecker, M., Hosoya, D., Hullo, M. F., Kakeshita, H., Karamata, D., Kasahara, Y., Kawamura, F., Koga, K., Koski, P., Kuwana, R., Imamura, D., Ishimaru, M., Ishikawa, S., Ishio, I., Le Coq, 
D., Masson, A., Mauel, C., Meima, R., Mellado, R. P., Moir, A., Moriya, S., Nagakawa, E., Nanamiya, H., Nakai, S., Nygaard, P., Ogura, M., Ohanan, T., O’Reilly, M., O’Rourke, M., Pragai, Z., Pooley, H. M., Rapoport, G., Rawlins, J. P., Rivas, L. A., Rivolta, C., Sadaie, A., Sadaie, Y., Sarvas, M., Sato, T., Saxild, H. H., Scanlan, E., Schumann, W., Seegers, J. F., Sekiguchi, J., Sekowska, A., Seror, S. J., Simon, M., Stragier, P., Studer, R., Takamatsu, H., Tanaka, T., Takeuchi, M., Thomaides, H. B., Vagner, V., van Dijl, J. M., Watabe, K., Wipat, A., Yamamoto, H., Yamamoto, M., Yamamoto, Y., Yamane, K., Yata, K., Yoshida, K., Yoshikawa, H., Zuber, U., and Ogasawara, N. (2003) Essential Bacillus subtilis genes. Proc. Natl. Acad. Sci. U.S.A. 100, 46784683.

(21) Uziel, O., Borovok, I., Schreiber, R., Cohen, G., and Aharonowitz, Y. (2004) Transcriptional regulation of the Staphylococcus aureus thioredoxin and thioredoxin reductase genes in response to oxygen and disulfide stress. J. Bacteriol. 186, 326-334.

(22) Björnberg, O., Efler, P., Ebong, E. D., Svensson, B., and Hägglund, P. (2014) Lactococcus lactis TrxD represents a subgroup of thioredoxins prevalent in Gram-positive bacteria containing WCXDC active site motifs. Arch. Biochem. Biophys. 564, 164-172.

(23) Jordan, A., Åslund, F., Pontis, E., Reichard, P., and Holmgren, A. (1997) Characterization of Escherichia coli NrdH. A glutaredoxin-like protein with a thioredoxin-like activity profile. J. Biol. Chem. 272, 18044-18050.

(24) Jordan, A., Pontis, E., Åslund, F., Hellman, U., Gibert, I., and Reichard, P. (1996) The ribonucleotide reductase system of Lactococcus lactis. Characterization of an NrdEF enzyme and a new electron transport protein. J. Biol. Chem. 271, 8779-8785.

(25) Efler, P., Kilstrup, M., Johnsen, S., Svensson, B., and Hägglund, P. M. (2015) Two Lactococcus lactis thioredoxin paralogues play different roles in responses to arsenate and oxidative stress. Microbiology, DOI: 10.1099/mic.0.000029.

(26) Björnberg, O., Maeda, K., Svensson, B., and Hägglund, P. (2012) Dissecting molecular interactions involved in recognition of target disulfides by the barley thioredoxin system. Biochemistry 51, 9930-9939.

(27) Maeda, K., Hägglund, P., Finnie, C., Svensson, B., and Henriksen, A. (2006) Structural basis for target protein recognition by the protein disulfide reductase thioredoxin. Structure 14, 17011710.

(28) Shahpiri, A., Svensson, B., and Finnie, C. (2008) The NADPHdependent thioredoxin reductase/thioredoxin system in germinating barley seeds: Gene expression, protein profiles, and interactions between isoforms of thioredoxin $\mathrm{h}$ and thioredoxin reductase. Plant Physiol. 146, 789-799.

(29) Williams, C. H., Zanetti, G., Arscott, L. D., and McAllister, J. K. (1967) Lipoamide dehydrogenase, glutathione reductase, thioredoxin reductase, and thioredoxin. J. Biol. Chem. 242, 5226-5231.

(30) Barkholt, V., and Jensen, A. L. (1989) Amino acid analysis: Determination of cysteine plus half-cystine in proteins after hydrochloric acid hydrolysis with a disulfide compound as additive. Anal. Biochem. 177, 318-322.

(31) Kirkensgaard, K. G., Hägglund, P., Shahpiri, A., Finnie, C., Henriksen, A., and Svensson, B. (2014) A novel twist on molecular interactions between thioredoxin and nicotinamide adenine dinucleotide phosphate-dependent thioredoxin reductase. Proteins 82, 607619.

(32) Magdenoska, O., Martinussen, J., Thykaer, J., and Nielsen, K. F. (2013) Dispersive solid phase extraction combined with ion-pair ultra high-performance liquid chromatography tandem mass spectrometry for quantification of nucleotides in Lactococcus lactis. Anal. Biochem. 440, 166-177.

(33) Dyson, H. J., Jeng, M. F., Tennant, L. L., Slaby, I., Lindell, M., Cui, D. S., Kuprin, S., and Holmgren, A. (1997) Effects of buried charged groups on cysteine thiol ionization and reactivity in Escherichia coli thioredoxin: Structural and functional characterization of mutants of Asp 26 and Lys 57. Biochemistry 36, 2622-2636.

(34) Heelis, P. F. (1982) The photophysical and photochemical properties of flavins (isoalloxazines). Chem. Soc. Rev. 11, 15-39.
(35) Harayama, T., Tezuka, Y., Taga, T., and Yoneda, F. (1984) Hydrolysis products of flavins (isoalloxazines). Tetrahedron Lett. 25, 4015-4018.

(36) Zanetti, G., Williams, C. H., Jr., and Massey, V. (1968) Influence of photoirradiation on the oxidation-reduction state of thioredoxin reductase. J. Biol. Chem. 243, 4013-4019.

(37) Kemal, C., Chan, T. W., and Bruice, R. C. (1977) Reaction of ${ }^{3} \mathrm{O}_{2}$ with dihydroflavins. 1. $\mathrm{N}^{3,5}$-Dimethyl-1,5-dihydrolumiflavin and 1,5-dihydroisoalloxazines. J. Am. Chem. Soc. 99, 7272-7286.

(38) Gadda, G. (2012) Oxygen activation in flavoprotein oxidases: The importance of being positive. Biochemistry 51, 2662-2669.

(39) McDonald, C. A., Fagan, R. L., Collard, F., Monnier, V. M., and Palfey, B. A. (2011) Oxygen reactivity in flavoenzymes: Context matters. J. Am. Chem. Soc. 133, 16809-16811.

(40) Yorita, K., Matsuoka, T., Misaki, H., and Massey, V. (2000) Interaction of two arginine residues in lactate oxidase with the enzyme flavin: Conversion of FMN to 8-formyl-FMN. Proc. Natl. Acad. Sci. U.S.A. 97, 13039-13044.

(41) Edmondson, D. E. (1974) Intramolecular hemiacetal formation in 8-formylriboflavine. Biochemistry 13, 2817-2821.

(42) Ohkawa, H., Ohishi, N., and Yagi, K. (1983) New metabolites of riboflavin appear in human urine. J. Biol. Chem. 258, 5623-5628.

(43) Ohkawa, H., Ohishi, N., and Yagi, K. (1983) Hydroxylation of the 7- and 8-methyl groups of riboflavin by the microsomal electron transfer system of rat liver. J. Biol. Chem. 258, 5629-5633.

(44) Mewies, M., McIntire, W. S., and Scrutton, N. S. (1998) Covalent attachment of flavin adenine dinucleotide (FAD) and flavin mononucleotide (FMN) to enzymes: The current state of affairs. Protein Sci. 7, 7-20.

(45) Edmondson, D. E., and Newton-Vinson, P. (2001) The covalent FAD of monoamine oxidase: Structural and functional role and mechanism of the flavinylation reaction. Antioxid. Redox Signaling 3, 789-806.

(46) Meah, Y., and Massey, V. (2002) Studies on 8-CHO-flavins, 8$\mathrm{CN}$-flavins and 8-CHO-flavoproteins. In Flavins and flavoproteins (Chapman, S. K., Perham, R., and Scrutton, N., Eds.) pp 281-286, Rudolf Weber, Berlin.

(47) Edmondson, D. E., and Ghisla, S. (1999) Electronic effects of 7 and 8 ring substituents as predictors of flavin oxidation-reduction potentials. In Flavins and flavoproteins (Ghisla, S., Kroneck, P., Macheroux, P., and Sund, H., Eds.) pp 71-76, Rudolf Weber, Berlin. (48) Losi, A., and Gartner, W. (2012) The evolution of flavin-binding photoreceptors: An ancient chromophore serving trendy blue-light sensors. Annu. Rev. Plant Biol. 63, 49-72.

(49) Losi, A., Polverini, E., Quest, B., and Gartner, W. (2002) First evidence for phototropin-related blue-light receptors in prokaryotes. Biophys. J. 82, 2627-2634.

(50) Nakano, S., Kuster-Schock, E., Grossman, A. D., and Zuber, P. (2003) Spx-dependent global transcriptional control is induced by thiol-specific oxidative stress in Bacillus subtilis. Proc. Natl. Acad. Sci. U.S.A. 100, 13603-13608.

(51) Dai, T., Gupta, A., Murray, C. K., Vrahas, M. S., Tegos, G. P., and Hamblin, M. R. (2012) Blue light for infectious diseases: Propionibacterium acnes, Helicobacter pylori, and beyond? Drug Resist. Updates 15, 223-236.

(52) Maclean, M., Macgregor, S. J., Anderson, J. G., and Woolsey, G. A. (2008) The role of oxygen in the visible-light inactivation of Staphylococcus aureus. J. Photochem. Photobiol., B 92, 180-184.

(53) Björnberg, O., Gruner, A. C., Roepstorff, P., and Jensen, K. F. (1999) The activity of Escherichia coli dihydroorotate dehydrogenase is dependent on a conserved loop identified by sequence homology, mutagenesis, and limited proteolysis. Biochemistry 38, 2899-2908.

(54) Higuchi, M., Yamamoto, Y., Poole, L. B., Shimada, M., Sato, Y., Takahashi, N., and Kamio, Y. (1999) Functions of two types of NADH oxidases in energy metabolism and oxidative stress of Streptococcus mutans. J. Bacteriol. 181, 5940-5947.

(55) Mishra, S., and Imlay, J. (2012) Why do bacteria use so many enzymes to scavenge hydrogen peroxide? Arch. Biochem. Biophys. 525, $145-160$. 
(56) Pericone, C. D., Overweg, K., Hermans, P. W., and Weiser, J. N. (2000) Inhibitory and bactericidal effects of hydrogen peroxide production by Streptococcus pneumoniae on other inhabitants of the upper respiratory tract. Infect. Immun. 68, 3990-3997.

(57) Leferink, N. G., Fraaije, M. W., Joosten, H. J., Schaap, P. J., Mattevi, A., and van Berkel, W. J. (2009) Identification of a gatekeeper residue that prevents dehydrogenases from acting as oxidases. J. Biol. Chem. 284, 4392-4397.

(58) Sun, W., Williams, C. H., Jr., and Massey, V. (1996) Sitedirected mutagenesis of glycine 99 to alanine in L-lactate monooxygenase from Mycobacterium smegmatis. J. Biol. Chem. 271, 17226-17233.

(59) Kirkensgaard, K. G., Hägglund, P., Finnie, C., Svensson, B., and Henriksen, A. (2009) Structure of Hordeum vulgare NADPHdependent thioredoxin reductase 2. Unwinding the reaction mechanism. Acta Crystallogr. D65, 932-941.

(60) Maeda, K., Hägglund, P., Björnberg, O., Winther, J. R., and Svensson, B. (2010) Kinetic and thermodynamic properties of two barley thioredoxin h isozymes, HvTrxh1 and HvTrxh2. FEBS Lett. 584, $3376-3380$.

(61) Zhao, G., Bruckner, R. C., and Jorns, M. S. (2008) Identification of the oxygen activation site in monomeric sarcosine oxidase: Role of Lys 265 in catalysis. Biochemistry 47, 9124-9135.

(62) Akif, M., Suhre, K., Verma, C., and Mande, S. C. (2005) Conformational flexibility of Mycobacterium tuberculosis thioredoxin reductase: Crystal structure and normal-mode analysis. Acta Crystallogr. D61, 1603-1611.

(63) Gustafsson, T. N., Sahlin, M., Lu, J., Sjöberg, B. M., and Holmgren, A. (2012) Bacillus anthracis thioredoxin systems, characterization and role as electron donors for ribonucleotide reductase. J. Biol. Chem. 287, 39686-39697. 